\title{
Tatarskij ènciklopedičeskij slovar'. Kazan, Institut Tatarskoj ènciklopedii AN RT, 1999, 703 p., ill., cartes. [Dictionnaire encyclopédique tatar]
}

\section{Stéphane A. Dudoignon}

\section{(2) OpenEdition}

Journals

Édition électronique

URL : http://journals.openedition.org/abstractairanica/36098

DOI : 10.4000/abstractairanica.36098

ISSN : 1961-960X

Éditeur :

CNRS (UMR 7528 Mondes iraniens et indiens), Éditions de l'IFRI

\section{Édition imprimée}

Date de publication : 15 mai 2001

ISSN : 0240-8910

\section{Référence électronique}

Stéphane A. Dudoignon, « Tatarskij ènciklopedičeskij slovar'. Kazan, Institut Tatarskoj ènciklopedii AN RT, 1999, 703 p., ill., cartes. [Dictionnaire encyclopédique tatar] », Abstracta Iranica [En ligne], Volume 22 | 2001, document 27, mis en ligne le 15 février 2010, consulté le 12 octobre 2020. URL : http:// journals.openedition.org/abstractairanica/36098; DOI : https://doi.org/10.4000/abstractairanica. 36098

Ce document a été généré automatiquement le 12 octobre 2020.

Tous droits réservés 


\title{
Tatarskij ènciklopedičeskij slovar'. Kazan, Institut Tatarskoj ènciklopedii AN RT, 1999, 703 p., ill., cartes. [Dictionnaire encyclopédique tatar]
}

\author{
Stéphane A. Dudoignon
}

Bien que rédigé dans un esprit qui est encore celui des encyclopédies soviétiques, le présent ouvrage constitue à ce jour la première publication de ce type consacrée spécifiquement à l'histoire et à la culture des Tatars de la Volga et de l'Oural, « des origines à nos jours ». Parmi les 16000 notices qui le composent, dont 7000 notices biographiques, on trouvera 閲 outre le curriculum d'une brochette de hiérarques locaux du PCUS 覧 nombre d'informations sur les personnalités les mieux documentées et sur les principales institutions communautaires de l'Islam de Russie entre la fin du $18^{\mathrm{e}} \mathrm{s}$. et le début $\mathrm{du} 20^{\mathrm{e}}$. Si la plupart des notices sont trop brèves pour s'avérer vraiment utiles aux chercheurs, elles offrent un état intéressant de la recherche et du discours historiques au Tatarstan à la fin des années 1990.

\section{INDEX}

Thèmes : 1.2. Recueils d'articles : revues, colloques, ouvrages collectifs 
AUTEURS

STÉPHANE A. DUDOIGNON

CNRS - Strasbourg 